\title{
PEMBELAJARAN DIMENSI TIGA MENGGUNAKAN PENDEKATAN PENDIDIKAN MATEMATIKA REALISTIK INDONESIA (PMRI) DI SMA NEGERI 2 TANJUNG RAJA
}

\author{
Norma Setiawati $^{1}$, Zulkardi $^{2}$, dan Cecil Hiltrimartin ${ }^{3}$ \\ 1orma_thsetia@yahoo.com \\ ${ }^{123}$ Pendidikan Matematika - FKIP Universitas Negeri Sriwijaya \\ 2016
}

\begin{abstract}
Abstrak
Penelitian ini bertujuan untuk mengetahui hasil pembelajaran dimensi tiga dengan menggunakan pendekatan Pendidikan Matematika Realistik Indonesia (PMRI) di SMA Negeri 2 Tanjung Raja. Metode penelitian yang digunakan dalam penelitian ini adalah penelitian desain. Sampel penelitian ini adalah kelas X D yang terdiri dari 26 siswa. Data dikumpulkan melalui dokumen dan tes. Berdasarkan hasil tes, diperoleh kesimpulan bahwa siswa lebih senang dengan pembelajaran dimensi tiga dengan menggunakan Pendidikan Matematika Realistik Indonesia di SMA Negeri 2 Tanjung Raja.
\end{abstract}

Kata Kunci: Pendekatan Pendidikan Matematika Realistik Indonesia (PMRI), Dimensi Tiga

\begin{abstract}
This research aims at recognizing the outcome of Indonesian Realistic Mathematics Education (IRME) based learning on the topic of three dimensional object at SMA Negeri 2 Tanjung Raja. The research method used was developmental research. The sample of the study was class X D that contained 26 students. Data was collected through documents and test. Based on the result of the test, it was obatined that students were feeling eager to engage the IRME based learning on the topic of three dimensional object.
\end{abstract}

Keywords: Indonesian Realistic Mathematics Education (IRME), three dimensional object

\section{Pendahuluan}

Sejak masih kecil, manusia telah di kenalkan dengan banyak hal yang berhubungan dengan matematika. Banyak di sekeliling manusia berimplementasi dari matematika. Yang terkadang sebagian kecil orang tidak menyadarinya. Hal ini menunjukkan pentingnya pembelajaran matematika di sekolah untuk kehidupan. Permendiknas No. 2 Tahun 2006 mengatur tujuan umum pendidikan matematika, diantaranya mengaplikasikan konsep matematika dalam pemecahan masalah dalam kehidupan.
Selain itu, Permendiknas (Depdiknas, 2006) mengatakan bahwa pendidikan matematika bertujuan agar siswa dapat menggunakan penalaran pada pola dan sifat, melakukan manipulasi matematika dalam membuat generalisasi, menyusun bukti atau menjelaskan gagasan dan pernyataan matematika. National Council of Teacher of Mathematics (NCTM, 2000) juga menyatakan tujuan pembelajaran matematika ada lima yaitu: kemampuan pemecahan masalah (problem solving), 
kemampuan penalaran (reasoning and proof), kemampuan komunikasi (communication), kemampuan koneksi (connections) dan kemampuan representasi (representation). Dari Permendiknas dan NCTM tersebut, dapat dilihat bahwa kemampuan yang harus dimiliki oleh siswa salah satunya adalah kemampuan penalaran.

Menurut Ambarsari (2012), dari hasil penelitian di kelas VII SMP N 6 Palembang disimpulkan bahwa kemampuan penalaran matematika siswa dengan menggunakan pendekatan pembelajaran Pendidikan Matematika Realistik Indonesia (PMRI) dilihat dari tingkat klasikalnya tergolong tinggi dengan rata-rata nilai tes kemampuan penalarannya adalah 72,59. Persentase siswa yang memiliki kemampuan penalaran sangat tinggi sebesar $15,79 \%$ dan persentase siswa yang memiliki kemampuan penalaran tinggi sebesar 47,37\% .

Menurut Zulkardi (2001), proses pembelajaran dengan menggunakan PMRI sangat menuntun siswa untuk mengembangkan ide-ide dan menumbuhkan kreativitas siswa dalam menyelesaikan masalah, dilihat dari proses yang dilakukan oleh siswa dalam menyelesaikan masalah.

Dari latar belakang yang telah diuraikan, maka peneliti merumuskan masalah yaitu: "Bagaimanakah pembelajaran dimensi tiga menggunakan pendekatan Pendidikan Matematika Realistik Indonesia (PMRI) di SMA Negeri 2 Tanjung Raja?". Sehingga penelitian ini bertujuan untuk mengetahui hasil pembelajaran dimensi tiga menggunakan pendekatan Pendidikan Matematika Realistik Indonesia (PMRI) di SMA Negeri 2 Tanjung Raja.

\section{Metode Penelitian}

Penelitian ini merupakan penelitian pengembangan yang bertujuan mengembangkan materi ajar dimensi tiga yang mengacu pada pendekatan PMRI. Subjek dalam penelitian ini adalah siswa kelas X D SMA Negeri 2 Tanjung Raja. Prosedur penelitian ini dibagi dalam dua tahap, yaitu:

\section{Self Evaluation}

a. Analisis

Analisis merupakan langkah awal dalam penelitian pengembangan. Analisis yang dimaksud meliputi analisis siswa, analisis kurikulum, dan analisis materi dimensi tiga yang akan dikembangkan menggunakan pendekatan PMRI yang sesuai KTSP SMP. Pada tahap ini, dilakukan juga analisis materi prasyarat yang harus dikuasai siswa untuk mempelajari materi dimensi tiga yaitu materi fungsi dan aljabar.

b. Pendesainan Materi Ajar

Pada tahap ini, dilakukan pendesainan materi ajar dimensi tiga menggunakan pendekatan PMRI dengan memperhatikan tiga prinsip dan lima karakteristik PMRI berupa Lembar Kerja Siswa (LKS).

2. Prototyping (validasi, evaluasi, dan revisi)

Pada tahap ini, draft yang telah dibuat di validasi, dievaluasi, kemudian direvisi. Langkahlangkah prototyping terdiri dari empat langkah yaitu, expert review, one-to-one evaluation, small group, dan field test.

a. Expert review

Draft hasil pendesainan oleh peneliti yang disebut sebagai draft prototype pertama diberikan kepada guru matematika, dosen, dan pakar PMRI. Pada tahap ini dilakukan uji validasi draft prototipe pertama yang meliputi kejelasan dan kebermaknaan gambar, tampilan buku siswa, kesesuaian konteks terhadap materi, keterurutan penyajian materi, dan mempresentasikan prinsip dan karakteristik PMRI. Dari uji validasi ini, akan diketahui kelemahan dari draft prototipe pertama serta didapat saran-saran dari pakar dan dosen pembimbing yang berguna dalam merevisi draft prototipe pertama.

\section{b. One-to-one evaluation}

Pada tahap one-to-one evaluation, peneliti memberikan draft prototipe pertama untuk diujicobakan kepada seorang siswa nonsubjek penelitian untuk menjawab pertanyaan-pertanyaan dalam lembar kerja siswa sesuai dengan waktu yang telah ditentukan. Pada pelaksanaannya peneliti berperan sebagai fasilitator yang membantu 
siswa jika menemukan kesulitan-kesulitan. Setelah menjawab pertanyaan-pertanyaan tersebut, siswa diminta untuk mengomentari lembar kerja siswa. Hasil uji coba dan tanggapan siswa dianalisis untuk melihat kendala-kendala yang dihadapi siswa dalam memahami materi yang disajikan dalam bentuk lembar kerja siswa sehingga dapat dijadikan masukan untuk revisi draft prototipe pertama.

c. Small group

Draft prototipe kedua yang merupakan hasil revisi draft prototipe pertama diujicobakan kepada non subjek penelitian yang berjumlah 5 orang. Kelompok kecil siswa diminta mengerjakan lembar siswa yang merupakan hasil pendesainan draft prototipe kedua. Pada pelaksanaannya, peneliti berperan sebagai fasilitator yang membantu siswa jika menemukan kesulitan-kesulitan. Setiap siswa diminta untuk memberikan pendapat dan saran setelah mengerjakan lembar kerja siswa yang didesain menggunakan pendekatan PMRI. Saran dan pendapat tersebut dijadikan sebagai bahan pertimbangan merevisi draft prototipe kedua.

\section{d. Field test}

Draft prototipe kedua yang telah direvisi berdasarkan saran dan pendapat pada tahap small group disebut draft prototipe ketiga yang dianggap valid. Draft prototipe ketiga ini akan diujicobakan ke lapangan (field test), yaitu subjek penelitian. Kemudian data yang dikumpulkan adalah data berupa hasil prototyping (validasi, evaluasi, dan revisi), dokumentasi, dan hasil tes. Tes diberikan untuk mengetahui hasil belajar siswa pada materi ruang dimensi tiga.

Skor komulatif yang diperoleh untuk hasil tes dan tugas dikonversasikan menjadi nilai dalam rentang $0-100$, dengan rumus:

$$
N_{i}=\frac{\text { Skor Kumulatif }}{\text { Skor Maksimum }} \times 100
$$

Kategori Penilaian Hasil Belajar Siswa
Tabel 1. Kategori Hasil Belajar Siswa

\begin{tabular}{|c|c|}
\hline Nilai Siswa & Kategori \\
\hline $85,1-100,0$ & Sangat baik \\
\hline $70,1-85,0$ & Baik \\
\hline $55,1-70,0$ & Cukup \\
\hline $40,1-55,0$ & Kurang \\
\hline $0-40$ & Sangat kurang \\
\hline
\end{tabular}

(modifikasi Arikunto, 2009: 245)

\section{Hasil dan Pembahasan \\ Hasil}

Penelitian ini dilaksanakan sebanyak 2 kali pertemuan, yaitu pada tanggal 3 Juni 2013 dan tanggal 5 Juni 20616. Siswa pada kelas X D SMA N 2 Tanjung Raja berjumlah 26 orang. Pada penelitian ini, siswa kelas X D berperan sebagai subyek penelitian.

Pada pertemuan pertama, peneliti menyampaikan materi tentang definisi titik, garis, dan bidang dalam ruang dimensi tiga, kedudukan titik terhadap garis dalam ruang dimensi tiga, kedudukan antara titik dan bidang dalam ruang dimensi tiga, dan kedudukan antara dua garis dalam ruang dimensi tiga.

Peneliti membuka pembelajaran dengan menyampaikan tujuan pembelajaran, yaitu siswa diharapkan mampu menentukan kedudukan antara dua titik dalam ruang dimensi tiga, menentukan kedudukan antara titik dan garis dalam ruang dimensi tiga, menentukan kedudukan antara titik dan bidang dalam ruang dimensi tiga, dan menentukan kedudukan antara dua garis dalam ruang dimensi tiga. Pada pertemuan ini siswa diberikan Lembar Kerja Siswa (LKS) yang berisi Lembar Aktivitas Siswa 1 dan Lembar Aktivitas Siswa 2. Pada Lembar Aktivitas Siswa 1 terdapat gambar contoh titik, garis, dan bidang dalam kehidupan sehari-hari. Peneliti mencontohkan bintang-bintang sebagai titik, kabel PLN sebagai garis, dan hamparan langit sebagai bidang. Pada Lembar Aktivitas 
Siswa 1 ini peneliti juga memberikan pertanyaan tentang kedudukan titik terhadap garis dengan memberikan gambar jembatan penyeberangan dan jalan sebagai garis, dan orang sebagai titik. Siswa juga diminta untuk mensketsakan antara jembatan penyebarangan, jalan, dan orang sebagai titik dan garis. Disana juga terdapat gambar beberapa burung sedang hinggap diatas kebelkabel PLN, siswa diminta menggambarkan kedudukan antara kabel sebagai garis dan burung sebagai titik.

Pada Lembar Aktivitas Siswa 2 terdapat beberapa pertanyaan disertai gambar dengan konteks sebuah bola basket yang berada di atas lantai, rel kereta api, serta denah lokasi. Siswa diminta menentukan kedudukan antara bola basket sebagai titik dan lantai sebagai bidang, kedudukan rel kereta api sebagai dua garis yang sejajar, dan kedudukan antara jalan-jalan yang ada pada denah lokasi.

Siswa sangat memperhatikan penjelasan dan bimbingan dari peneliti. Semua dari mereka seoerti ingin lebih mengetahui dengan pelajaran yang diberikan.

Pada pertemuan kedua, peneliti menyampaikan materi tentang kedudukan antara garis dan bidang dalam ruang dimensi tiga, serta kedudukan antara dua bidang dalam ruang dimensi tiga. Peneliti membuka pembelajaran dengan mengingatkan siswa pada pertemuan sebelumnya. Dilanjutkan dengan menyampaikan tujuan pembelajaran pertemuan kedua, yaitu siswa diharapkan mampu menentukan kedudukan antara garis dan bidang dalam ruang dimensi tiga, dan mampu menentukan kedudukan antara dua bidang dalam ruang dimensi tiga.

Pada kegiatan ini, peneliti memberikan Lembar Aktivitas Siswa 3 kepada siswa secara berkelompok seperti pada pertemuan pertama dan memberikan tes evaluasi secara individu. Di dalam Lembar Aktivitas Siswa 3 ini terdapat tujuan pembelajaran dan pertanyaan-pertanyaan tentang kedudukan antara titik dan bidang serta kedudukan dua garis dalam ruang dimensi tiga. Terdapat gambar konteks tentang proses pengibaran bendera, dan dua buah dinding dengan jalan ditengahnya. Siswa diminta 54 menentukan kedudukan alas tiang bendera sebagai bidang dan tiang sebagai garis, serta dinding sebagai ruang dan jalan sebagai garis.

Dalam mengerjakan Lembar Aktivitas Siswa 3, sebagian besar dari mereka keliru mengisi pertanyaan nomor 3 , tentang sudut yang dibentuk antara tiang dan bendera. Seharusnya sudut yang benar adalah $90^{\circ}$, tetapi mereka mengisi $180^{\circ}$. Sepertinya penguasaan materi tentang besar sudut mereka kurang atau mereka lupa bahwa sudut siku-siku adalah $90^{\circ}$. Mereka begitu aktif dalam pembelajaran ini. Sebagian besar siswa tidak malu untuk bertanya kepada peneliti.

Kegiatan selanjutnya dengan memberikan tes evaluasi kepada setiap siswa untuk melihat hasil belajar siswa terhadap materi yang disampaikan peneliti. Pada tes tertulis ini, peneliti memberikan 5 soal kepada siswa yang berhubungan dengan kompetensi dasar, yaitu menentukan kedudukan titik, garis, dan bidang dalam ruang dimensi tiga.

Pada akhir pertemuan, peneliti mengucapkan terimakasih kepada siswa atas partisipasinya dalam penelitian ini, dan menyampaikan bahwa matematika ada disekitar kita dalam kehidupan sehari-hari. Tidak ada yang tidak berkaitan dengan matematika.

Tabel 2. Tingkat Penguasaan Siswa Pada Tes Akhir

\begin{tabular}{|c|c|c|}
\hline $\begin{array}{c}\text { Tingkat } \\
\text { Penguasaan }\end{array}$ & $\begin{array}{c}\text { Banyak } \\
\text { Siswa }\end{array}$ & $\begin{array}{c}\text { Persentase } \\
\text { Jumlah Siswa }\end{array}$ \\
\hline S. Rendah & 0 & $0 \%$ \\
\hline Rendah & 0 & $0 \%$ \\
\hline Sedang & 12 & $46 \%$ \\
\hline Tinggi & 13 & $50 \%$ \\
\hline S. Tinggi & 1 & $4 \%$ \\
\hline \multicolumn{2}{|c|}{ Jumlah } & $100 \%$ \\
\hline
\end{tabular}

\section{Pembahasan}

Berdasarkan hasil penelitian, hasil pembelajaran dimensi tiga dengan menggunakan pendekatan Pendidikan Matematika Realistik Indonesia yang dilakukan peneliti dapat dikatakan sudah cukup baik untuk meningkatkan prestasi 
pada siswa. Dengan menggunakan konteks dalam kehidupan sehari-hari siswa lebih dapat memahami matematika dengan baik dan menyenangkan. Saat proses pembelajaran, peneliti menggunakan Lembar Kerja Siswa (LKS) dengan konteks bermacam-macam agar siswa mampu mempelajari dimensi tiga dengan baik.

Saat proses pembelajaran, peneliti menggunakan Lembar Kerja Siswa (LKS) dengan konteks bermacam-macam agar siswa mampu mempelajari dimensi tiga dengan baik. Seperti pada Lebar Aktivitas 1 siswa diminta membuat sketsa garis dan titik dengan konteks burung yang sedang bertengger di atas kabel listrik.

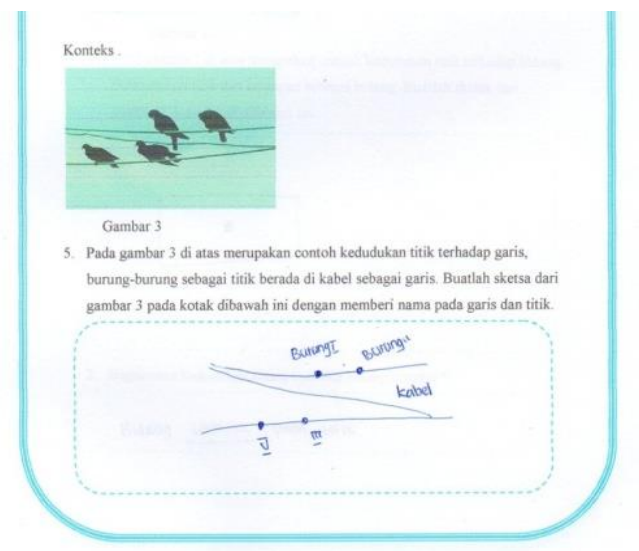

Gambar 1. Respon siswa pada LAS 1 soal no. 5

Pada lembar Aktivitas Siswa 2 terdapat gambar denah jalan agar siswa dapat mempelajari kedudukan antara garis dengan garis dalam ruang dimensi tiga tanpa adanya kesulitan.

Siswa mengerjakan tes evalausi yang diberikan peneliti mengenai tempat kedudukan pada ruang dimensi tiga. Sebagian besar siswa tidak mengalami kesulitan dalam menyelesaikannya, sehingga hasil evaluasi siswa dapat dikatakan tinggi.

\section{Kesimpulan}

Berdasarkan hasil penelitian, diperoleh kesimpulan bahwa terdapat peningkatan hasil pembelajaran dimensi tiga menggunakan pendekatan Pendidikan Matematika Realistik Indonesia (PMRI) di SMA Negeri 2 Tanjung Raja, yang ditandai dengan adanya peningkatan nilai dari siswa.
Adapun beberapa saran dari peneliti setelah melaksanakan penelitian ini, yaitu:

1. Siswa, sebaiknya lebih membiasakan belajar matematika dengan melihat pada kehidupan sehari-hari agar pembelajaran matematika lebih menyenangkan dan tidak membosankan.

2. Guru mata pelajaran matematika, penelitian ini diharapkan dapat menjadi salah satu rujukan agar dapat membantu siswa belajar matematika lebih mudah dalam memahami agar dapat meningkatkan kemampuan matematika mereka.

3. Sekolah, penelitian ini diharapkan sebagai referensi agar siswa senang dalam pembelajaran matematika. 
JURNAL GANTANG Pendidikan Matematika FKIP - UMRAH

Vol. 1 No. 2, Desember 2016, p-ISSN. 2503-0671, e-ISSN. 2548-5547

Referensi

Ambarsari, S. (2012). Kemampuan Penalaran Matematika Siswa dengan Menggunakan Pendekatan PMRI di Kelas VII SMP N 6 Palembang. Skripsi. Indralaya: FKIP Universitas Sriwijaya.

Arikunto. (2009). Dasar-Dasar Evaluasi Pendidikan. Jakarta: Bumi Aksara.

Depdiknas. (2006). Kurikulum Tingkat Satuan Pendidikan. Jakarta: Depdiknas.

NCTM. (2000). Principle and Standards for School Mathematics. USA: NCTM www.nctm.org

Zulkardi. (2001). Karakteristik PMRI. http://www.reocities.com/ratuilma/tutorfr amesetindo.html diakses 2 Mei 2012. 